V Congresso Brasileiro de Informática na Educação (CBIE 2016)

Anais do XXVII Simpósio Brasileiro de Informática na Educação (SBIE 2016)

\title{
Geography History: Um aplicativo para auxílio ao ensino de Geografia
}

\author{
Dorgival Netto ${ }^{1}$, Gleydson Silva ${ }^{2}$, Hugo de Melo², Vitor da Costa ${ }^{2}$ \\ ${ }^{1}$ Centro de Informática - Universidade Federal de Pernambuco (UFPE) \\ Recife - PE - Brasil \\ ${ }^{2}$ Faculdade Maurício de Nassau \\ João Pessoa - PB - Brasil \\ dpsn2@cin.ufpe.br, \{gleydson962, hugomelohm17, vit20142015\}@gmail.com
}

\begin{abstract}
Geography has been going every day for changes in its teaching methods. With advances in technologies applied to education, the classes can become more dynamic and exciting. These technologies can be used to assist in understanding and make broader themes that are covered in the classroom. Based on this, we aim to to develop an app for the helping to the discipline of Geography from 6th to 9th of Basic Education which deals with the political division, vegetation, topography, climate, hydrography of South American countries.
\end{abstract}

Resumo. A Geografia vem passando a cada dia por alterações em sua metodologia de ensino. Com os avanços das tecnologias aplicadas na educação, as aulas podem tornar-se mais dinâmicas e instigantes. Assim, estas tecnologias podem ser utilizadas para auxiliar na compreensão e tornar mais abrangentes os temas que são abordados em sala de aula. Com base nisto, temos por objetivo desenvolver um aplicativo para o auxílio à disciplina de Geografia do $6^{\circ}$ ao $9^{\circ}$ do Ensino Fundamental que trata da divisão política, vegetação, relevo, clima, hidrografia dos países da América do Sul.

\section{Introdução}

A disciplina de Geografia é um componente curricular do Ensino Fundamental onde os alunos são motivados a estudar as Ciências Naturais como, por exemplo, a Geologia, a Oceanografia, a Climatologia, as Ciências Sociais como, por exemplo, Economia e Sociologia. Esta disciplina aborda aspectos que ocorrem diariamente, mas, mesmo assim, ainda possui uma abordagem de ensino bastante tradicional baseada, essencialmente, na memorização. De acordo com Straforini (2004), o aluno é colocado de forma passiva, como um receptáculo de um bloco de conhecimentos fragmentados e hierarquizados, para serem memorizados e reproduzidos. Cavalcanti (2012) afirma que é necessário ensinar-lhes modos de pensamento e ação, ou seja, por meio de atividades proporcionadas nas aulas os professores devem estimular o desenvolvimento de certas capacidades e habilidades. De acordo com Sá Filho e Machado (2011) a informática pode ser um recurso auxiliar para a melhoria do processo de ensino e aprendizagem, no qual o foco da educação passa a ser o aluno, construtor de novos conhecimentos, em um ambiente construcionista, contextualizado e significativo, definido por Valente (2002) como um ambiente favorável que desperta interesse do aluno e o motive a explorar, a pesquisar, a descrever, a refletir e a depurar suas ideias.

Atualmente, os computadores deixaram de ser o único meio de acesso a informação tecnológica e, com o advento dos dispositivos móveis e da conectividade, o uso de smartphones e tablets passam a fazer parte deste cenário. O TIC Kids Online Brasil (2014) é um estudo realizado pelo Comitê Gestor da Internet que gera indicadores sobre os usos que crianças e adolescentes de 9 a 17 anos de idade fazem da Internet. Esta pesquisa visa 
entender a percepção de jovens em relação à segurança on-line, bem como delinear as práticas de mediação de pais e responsáveis relacionadas ao uso da Internet. Na pesquisa realizada em 2014, cerca de $81 \%$ da amostra dos participantes acessam todos os dias ou quase todos os dias. Em 2013, apenas $63 \%$ possuíam a mesma frequência de acesso. Destes, $82 \%$ acessam de celulares, $32 \%$ de tablets, enquanto $56 \%$ de computadores de mesa ou notebooks. Assim, percebemos que o acesso à internet através de smartphones e tablets superou o de computadores ou notebooks [TIC Kids, 2014].

As informações apresentadas anteriormente apenas reforçam que o paradigma educacional de aprendizagem móvel (do inglês, mobile learning) deve ser mais explorado. $\mathrm{O}$ mobile learning ou m-learning é a fusão de diversas tecnologias de processamento e comunicação de dados que permite ao grupo de estudantes e aos professores uma maior interação [Pelissoli e Loyola, 2004]. Como cita Marçal et al. (2013), vários autores já comprovaram os benefícios do uso desses dispositivos para propósitos educacionais e demonstraram que a introdução da computação móvel na sala de aula motiva o aprendizado, a colaboração e a comunicação entre os alunos [Viana et al., 2011] [Sanchez et al., 2009].

Os aplicativos no ensino trazem uma maior atratividade e interatividade aos alunos, fazendo com que eles se sintam cada vez mais estimulados e seu aprendizado seja prático e fácil para um melhor desenvolvimento na formação dos mesmos em sala de aula. Os aplicativos podem ser utilizados como forma de interação na metodologia de ensino dos professores, a complementação do ensino do dia a dia, torna-se uma forma mais prazerosa e acessível para os alunos que estão cada vez mais com os smartphones em seu cotidiano.

O Geography History é um aplicativo desenvolvido para Android que tem o propósito de trazer os conteúdos da disciplina de Geografia que estão sendo aplicados em sala de aula para os smartphones, visando proporcionar interatividade entre aluno e disciplina ampliando o acesso aos conteúdos de sala de aula. O aplicativo consiste do mapa da América do Sul com suas divisões políticas. Ao clicar em cada país trará ao usuário informações sobre o país requisitado como, por exemplo, os climas em que nele há, as vegetações, relevos, hidrografia, população, moeda, língua oficial, entre outras.

Este artigo está dividido em seis partes. Após a discussão sobre as motivações, a Seção 2 trata do uso de jogos educativos no processo de aprendizagem, na Seção 3 são apresentados os trabalhos relacionados na literatura, a Seção 4 descreve o Geography History, enquanto na Seção 5 é apresentado o resultado da avaliação preliminar do aplicativo e, por fim, a Seção 6 traz as considerações e os trabalhos futuros.

\section{Softwares relacionados}

Geography Quiz (2016) é um aplicativo gratuito que consiste de um quiz de perguntas e respostas, possibilitando ao jogador adquirir novos conhecimentos. O jogador faz parte de uma corrida ao redor do mundo, com outros jogadores, iniciando na cidade de Nova Iorque. O primeiro jogador a chegar de volta a Nova Iorque, vence.

Onde é isso (Hillebrand, 2016) é um aplicativo que ajuda o jogador a conhecer o mundo, aprendendo sobre Países, Capitais, Cidades, Estados, estádios, montanhas e arranha-céus de diversos países. Cada local está conectado com a Wikipédia, de modo que o jogador possa ler sobre cada local imediatamente, em seu idioma. O professor de geografia pode colocar até 8 alunos para jogar simultaneamente.

Em comparação aos aplicativos citados a cima o Geography History será desenvolvido para o auxílio das aulas em sala, fazendo com que os alunos expandam e melhorem seus conhecimentos e conheçam nosso continente cada vez mais. $\mathrm{O}$ aplicativo tem por intuito trazer o continente Sul-Americano com informações gerais dos países neles existentes, tais 
como: clima, relevo, vegetação, hidrografia, etc. O aplicativo tem o objetivo de ser utilizado como um recurso que auxiliará docentes e discentes no cotidiano escolar.

\section{GeographyHistory}

O aplicativo foi desenvolvido na linguagem Java utilizando a ferramenta Android Studio, para o banco de dados utilizamos o SQLite e sua modelagem está sendo feita no astah. Na elicitação de requisitos foram realizadas pesquisas na bibliografia e entrevistas semiestruturadas com professores da disciplina de Geografia de escolas públicas, onde apresentamos a ideia do projeto e perguntamos aos mesmos, o que mudaria na metodologia de ensino da disciplina e o quanto os auxiliariam durante e após as aulas o desenvolvimento de um aplicativo. Quais os conteúdos que eles consideravam mais importantes, inicialmente, para se fazer presente no aplicativo. Assim, percebemos que era viável e importante o desenvolvimento de um aplicativo que pudesse auxiliar docentes e discentes no processo de ensino aprendizagem da disciplina.

O Geography History é um aplicativo educacional, gratuito que está disponível na plataforma Android com intuito de trazer aos jovens do $6^{\circ}$ ao $9^{\circ}$ ano a facilidade de aprendizagem na disciplina de Geografia, contendo o mapa do continente Sul-Americano, apresentando as peculiaridades e diversidades de cada país do nosso continente com informações sobre os países neles existentes como, por exemplo, clima, relevo, vegetação e hidrografia. Haverá links externos para um maior aprendizado dos alunos, buscando facilitar o processo de ensino-aprendizagem dos conteúdos da disciplina.

A Figura 1 (a) apresenta a tela inicial do Geography History que exibe as opções de realizar o cadastro ou efetuar o login. A tela de cadastro é apresentada na Figura 1 (b), tem como papel solicitar todas as informações do usuário para o preenchimento de todos os campos necessários para que o aplicativo possa montar um perfil dos usuários que estão utilizando o aplicativo. Nesta tela será solicitado o nome completo do aluno, sua escola, ano de ensino, e-mail e senha. O e-mail e a senha também serão necessários para efetuar o login. A tela de cadastro ainda vai conter um campo para telefone, caso necessite de algum contato via SMS ou até mesmo através de ligação. Após efetuar o cadastro o usuário será redirecionado para a tela de login, Figura 1 (c), nesta tela será solicitado respectivamente o e-mail e senha cadastrados pelo usuário. A tela de pesquisa contará com duas opções a de ir ao mapa ou referências. Caso escolha a opção de referência o usuário terá acesso a links complementares onde poderá buscar mais informações a respeito dos conteúdos abordados.

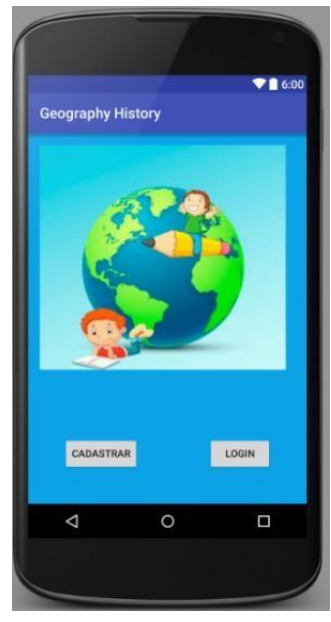

a. Tela Inicial

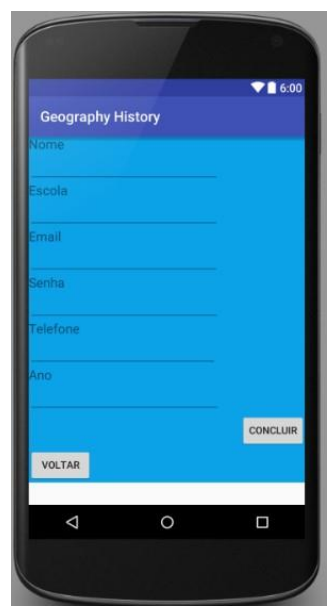

b. Tela de Cadastro

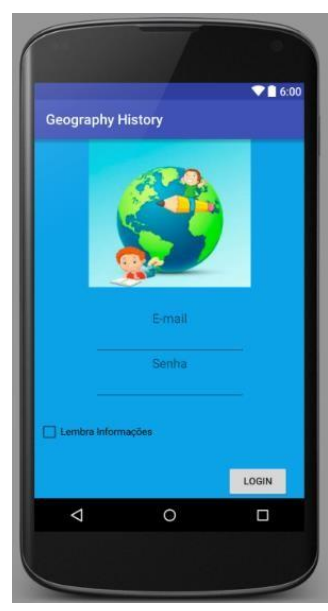

c. Tela de Login

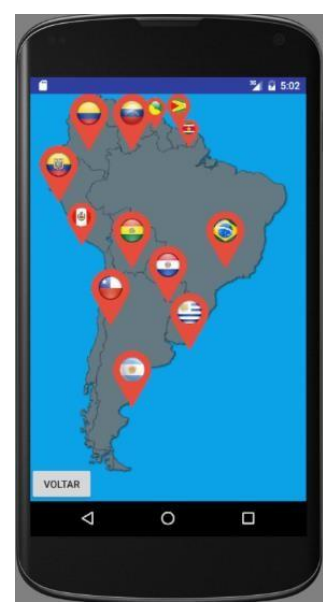

d. Tela do Mapa

Figura 1. Telas do aplicativo Geography History 
Ao escolher a opção mapa ele será redirecionado para tela onde haverá o mapa da América do Sul e seus respectivos países, apresentada, apresentada na Figura 1 (d), permitindo ao usuário escolher o país desejado. Ao selecionar o país ele será redirecionado para tela que constará as informações dos temas que são mais abordados em sala de aula, tais como: clima, vegetação, relevo, espécies nativas, hidrografia e informações gerais. A Figura 2 (a) apresenta a tela do país com as informações disponíveis (clima, vegetação, relevo, espécies nativas, hidrografia e informações gerais). Como exemplo, a Figura 2 (b) apresenta as informações gerais do Brasil como, por exemplo, capital, idioma oficial, moeda, religiões e, a Figura (c) apresenta as informações referente a hidrografia do Brasil.

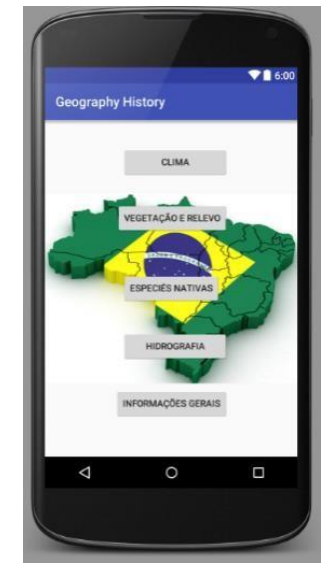

a. Tela do País

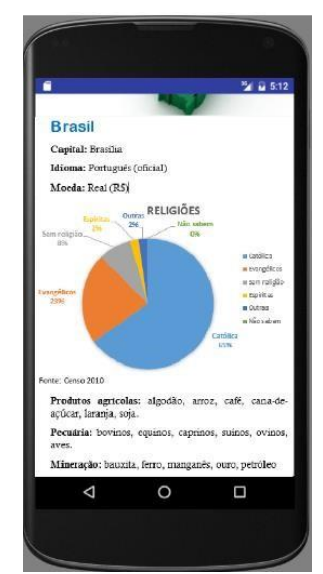

b. Tela de Infomações Gerais

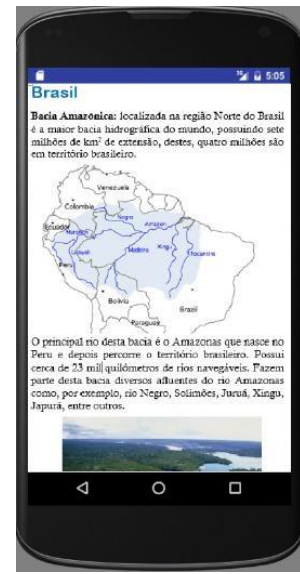

c. Tela de Hidrografia

Figura 2. Telas do Geography History exibindo as informações de um país

\section{Avaliações preliminares}

Após o desenvolvimento do Geography History nos encontramos novamente com os professores que participaram do processo de elicitação de requisitos para apresentar o aplicativo e verificar as impressões a respeito do mesmo. Segue abaixo alguns trechos das respostas dos professores:

"Acredito que este aplicativo irá dinamizar as aulas facilitando o nosso trabalho e incentivando os alunos a utilizarem a tecnologia a seu favor". [Entrevistado 01]

"O aplicativo flexibiliza a rigidez do currículo e quebra a ênfase no conteúdo. Principalmente na era da informação, em que o meio técnico-cientifico informacional é sinônimo de dominação. E isso chama muita a atenção dos alunos". [Entrevistado 02]

"Aumenta a interação dos alunos com a disciplina, pois a disciplina é muito teórica e isto acaba com que os alunos percam um pouco o foco. Pois facilitara na metodologia de aplicação da disciplina". [Entrevistado 03]

\section{Considerações e trabalhos futuros}

Este artigo apresentou o Geography History, um aplicativo android que tem como objetivo auxiliar o processo de ensino-aprendizagem da disciplina de Geografia nas turmas do $6^{\circ}$ ao $9^{\circ}$ ano do Ensino Fundamental. De acordo com a avaliação preliminar dos professores que participaram do processo de elicitação de requisitos, o aplicativo tende a ser bem aproveitado em sala e auxiliar os alunos no processo de ensino-aprendizagem da disciplina de Geografia. Pretendemos realizar uma avaliação com os alunos que se enquadram no público-alvo, visando identificar aspectos pedagógicos e de usabilidade que precisem de melhorias para atingir o objetivo do aplicativo com qualidade. Para as próximas versões do 
V Congresso Brasileiro de Informática na Educação (CBIE 2016)

Anais do XXVII Simpósio Brasileiro de Informática na Educação (SBIE 2016)

Geography History pretendemos inserir o mapa-mundi trazendo informações de todos os países e, um quiz sobre os temas abordados no aplicativo, subdivididos por cada continente e dando uma ênfase maior ao Brasil por ser o país onde o aplicativo será utilizado nas escolas.

\section{Referências}

Cavalcanti, L. de S. Concepções de Geografia e de Geografia Escolar no Mundo Contemporâneo. IN: A Geografia Escolar e a Cidade: Ensaios sobre o Ensino de Geografia para a vida Urbana Cotidiana. $3^{a}$ Edição. Campinas, SP: Papirus, 2012. Pp 1537.

Geography Quiz: Jogo de perguntas de geografia. Disponível em: https://play.google.com/store/apps/details?id=com.Geography.Quiz.Game\&hl=pt-BR. Acesso em 04 de junho de 2016.

Hillebrand, Jaysquared. Onde é isso? Geografia quis. Disponível em: https://itunes.apple.com/br/app/onde-e-isso-geografia-quiz/id492240967?mt=8. Acesso em 03 de abril de 2016.

Marçal, E; Andrade, R.; Viana, W.; Rodrigues, D.; Maia, M.; Mendes, W.; Freire, J.; Benicio, W. Geomóvel: Um aplicativo para auxílio a aulas de campo de Geologia. In: Simpósio Brasileiro de Informática na Educação, 2013.

Pelissoli, L.; Loyolla, W. (2004). Aprendizado móvel (m-learning): dispositivos e cenários. In: $11^{\circ}$ Congresso Internacional de Educação a Distancia, 2004. Disponível em: http://www.abed.org.br/congresso2004/por/htm/074-TC-C2.htm. Acesso em: 03/2016.

Sá Filho, C. S.; Machado, E. C. O computador como agente transformador da educação e o papel do objeto de aprendizagem. Disponível em: . Acesso em: 16 nov. 2011.

Sánchez J., Sáenz M., Muñoz, M., Ramirez G. e Martín S. (2009) Solite Situación actual del m-learning. Primer Informe Público. Disponível em: http://remo.det.uvigo.es/solite/

Straforini, R. Dilemas do Ensino de Geografia. IN: Ensinas Geografia: o desafio da totalidade-mundo nas séries iniciais. São Paulo: Annablume, 2004. Pp. 45-74.

Tadiotto, Luciana Bedin; Bogado, Samir Sogado; Spanceski, Janice Licieski. O ensino de Geografia e o aprendizado na escola. Disponível em: <www.faesi.com.br/nucleodepesquisa-cientifica/75-portal-do-saber/220-o-ensino-de-geografia-e-o-aprendizadonaescola Acesso em 10 abril de 2016.

Tic Kids Online Brasil: Percepção de jovens em relação à segurança on-line, bem como delinear as práticas de mediação de pais e responsáveis relacionadas ao uso da Internet (2014). Disponível em: http://data.cetic.br/cetic/explore?idPesquisa=TIC_KIDS. Acesso em 22 de abril de 2016.

Valente, J. A. A espiral da aprendizagem e as tecnologias da informação e comunicação: repensando conceitos. In: JOLY, M. C. R. A. Tecnologia no ensino: implicações para a aprendizagem. São Paulo: Casa do Psicólogo, 2002.

Viana, W., Andrade, R. M. C., Maia, M., Marçal, E., Gensel, J., Lima, J. V, Junior, J. C. e Sanchez, J. (2011). Towards context-aware and mobile e-learning application. In: TISE 2011, Congreso Internacional de Informática Educativa, 2011, Santiago, Chile. 